\title{
EDITORIAL
}

\section{In This Issue: Nothing Simple}

\author{
Kurt C. Stange, Editor
}

Ann Fam Med 2018;16:386-387. https://doi.org/10.1370/afm.2302

$\mathrm{T}$ here are not a lot of simple answers in this issue of Annals. The complexity of the questions being posed, and the health and health care phenomena that are being evaluated, defy easy answers.

A research study, an essay, and an editorial address the effects of social isolation and loneliness-among patients and primary care clinicians - on health and health care. Fukuhara et al study elderly patients from a Japanese primary care practice-based research network, and find that social isolation is negatively associated with several important domains of primary care service delivery. ${ }^{1}$ An essay by Frey exposes the experience and implications of loneliness and isolation among physicians, and the reduction in forums for personal professional interaction. ${ }^{2}$ An editorial by Daaleman interprets the linkages between loneliness, social isolation, and health. ${ }^{3}$

Dizziness can be challenging to evaluate. Stam et al develop and evaluate a risk scoring system that provides fairly good discrimination of people with an unfavorable course of dizziness, which was observed in nearly three-quarters of the development cohort and less than one-half of the validation cohort. ${ }^{4}$ An accompanying editorial by Wallace and Johansen considers challenges and opportunities in the evaluation and implementation of clinical prediction rules. ${ }^{5}$

Keeping up with burgeoning clinical knowledge is not simple, but Patient Oriented Evidence that Matters (POEMs) has made the task easier by identifying and summarizing scientific evidence relevant to primary care. Ebell and colleagues summarize the POEMs for each of the last 20 years that were highest ranked for having recommended a major and persistent change in practice. The recommended changes include new effective interventions, or abandoning ineffective or potentially harmful practices. The authors rightly note that these articles reflect the breadth of primary care. ${ }^{6}$

The adoption of an electronic health record tool for screening for social determinants of health is evaluated by Gold et al, using both quantitative and qualitative methods. They find that nearly all patients screened in 3 community health centers have at least 1 social determinant need documented in the electronic health record, but less than one-quarter indicate wanting help with this need. ${ }^{7}$
Interventions to address employment as a social determinant of health are assessed in a systematic review by Pinto and colleagues. Among 88 studies meeting inclusion criteria, they find that most studies focus on people with mental illness, and the majority are successful in helping participants gain employment. They also identify characteristics of successful interventions. ${ }^{8}$

In nationally representative data, Wang et al test the interesting hypothesis that intake of high levels of free fructose, such as sweeteners containing highfructose corn syrup, is associated with allergic symptoms or sensitization among children and adolescents. The results are not completely consistent, but the pattern seems worthy of further investigation, and perhaps even clinical action among children at high risk. ${ }^{9}$

In a study of initial patient enrollment in a medical home mandated to provide after-hours care, Kiran et al find increases in the rate of emergency department visits and the proportion of primary care visits occurring on the weekend, and a decrease in the overall primary care visit rate..$^{10}$ Contextual factors seem important in interpreting these findings from Ontario, Canada.

Two research briefs address the ability of primary care to mitigate the opioid crisis. Hallvik et al find that continuity of care is inversely associated with filling risky opioid prescriptions and with overdose hospitalizations. ${ }^{11}$ Tong et al find that in a 2016 national survey of family medicine residency graduates, $10 \%$ report preparedness to provide buprenorphine treatment and $7 \%$ report current prescribing. ${ }^{12}$ Although many factors are involved, efforts to support continuity of care, and residency training in medication-assisted treatment could help primary care to reduce risk in both the initial prescribing and the deprescribing ends of the opioid overuse problem.

Four contributions to the Annals of Family Medicine feature on Innovations in Primary Care in this issue share novel approaches to: obtaining a sexual history from patients using a simple visual technique during the clinical encounter, ${ }^{13}$ rapidly scaling integrated behavioral and primary care across a large regional health care system, ${ }_{1}^{14}$ providing mentored training positions for early career general practitioners, ${ }^{15}$ and using 
a Humanism Pocket Tool to assist with the care of patients with challenging behaviors. ${ }^{16}$

We welcome you to join the online discussion for each of these and previously published articles at http://www.AnnFamMed.org.

The Annals joins the Journal of the American Board of Family Medicine and Family Medicine in growing concerns about predatory journals, ie, journals that do not meet accepted standards for professional scientific publication, posing potential risks to authors. The 3 journals have collaborated on an editorial with helpful resources on this timely issue, at http://www.jabfm.org/ content/31/5/671.

With this issue, Annals also marks 3 transitions. We are grateful to Rob Williams and Lars Peterson who have completed their service as associate editors, and to Gerardo Moreno who joins the team as a new associate editor. Rob has been exemplary at providing authors with helpful feedback across a wide variety of manuscripts. He continues as a Distinguished Professor of Family and Community Medicine at the University of New Mexico School of Medicine, working with and for underserved populations, and is enjoying his new role as a grandfather. Lars provided Annals with a valuable policy perspective, strong methods skills, and youthful energy. He continues as Research Director at the American Board of Family Medicine. Gerardo is Associate Professor of Family Medicine at the University of California, Los Angeles, David Geffen School of Medicine, and Director of UCLA PRIME-LA (Program in Medical Education) which focuses on Leadership and Advocacy for underserved communities. He has been an outstanding reviewer for Annals, and we look forward to his new role as associate editor.

\section{References}

1. Aoki T, Yamamoto $Y$, Ikenoue T, et al. Social isolation and patient experience in older adults. Ann Fam Med. 2018;16(5):393-398.

2. Frey III JJ. Professional loneliness and the loss of the doctors' dining room. Ann Fam Med. 2018;16(5):461-463.
3. Daaleman TP. The long loneliness of primary care. Ann Fam Med. 2018;16(5):388-389.

4. Stam H, Maarsingh OR, Heymans MW, van Weert HCPM, van der Wouden JC, van der Horst HE. Predicting an unfavorable course of dizziness in older patients. Ann Fam Med. 2018;16(5):428-435.

5. Wallace $E$, Johansen ME. Clinical prediction rules: challenges, barriers, and promise. Ann Fam Med. 2018;16(5):390-392.

6. Ebell MH, Barry HC, Shaughnessy AF, Slawson D, Kulkarni N, Speer L. Top 20 POEMs of the past 20 years: a survey of practicechanging research for family physicians. Ann Fam Med. 2018;16(5): 436-439.

7. Gold R, Bunce A, Cowburn S, et al. Adoption of social determinants of health EHR tools by community health centers. Ann Fam Med. 2018;16(5):399-407.

8. Pinto AD, Hassen N, Craig-Neil A. Employment interventions in health settings: a systematic review and synthesis. Ann Fam Med. 2018;16(5):447-460.

9. Yu R, Yang B, Cai L, Lu X, Wang X. Excess free fructose beverages and allergy in children and adolescents: Results from NHANES 2005-2006. Ann Fam Med. 2018;16(5):408-418.

10. Kiran T, Moineddin R, Kopp A, Frymire E, Glazier RH. Emergency department use and enrollment in a medical home providing afterhours care. Ann Fam Med. 2018;16(5):419-427.

11. Hallvik SE, Geissert P, Wakeland W, et al. Opioid-prescribing continuity and risky opioid prescriptions. Ann Fam Med. 2018;16(5): 440-442.

12. Tong ST, Hochheimer CJ, Peterson LE, Krist AH. Buprenorphine provision by early career family physicians. Ann Fam Med. 2018;16(5): 443-446.

13. Kole J. Circling back to a better sexual history. Ann Fam Med. 2018; 16(5):465.

14. Stoeckle J, Cunningham A, Arenson C. Scaling integrated behavioral health rapidly. Ann Fam Med. 2018;16(5):464.

15. Weatherburn CJ, Hasan S, Watts M, Shaw D. Mentored training positions for early-career general practitioners. Ann Fam Med. 2018; 16(5):466.

16. Soh M, Shaner A, Gelberg L, Kopelson K, Stuber M, Fessler D, Warde C. Using the humanism pocket tool for patients with challenging behaviors. Ann Fam Med. 2018;16(5):467. 